The Journal of

Thoracic and Cardiovascular

Surgery

Vol 128, No. 2, August 2004

\title{
Regional myocardial ischemia in hypertrophic cardiomyopathy: Impact of myectomy
}

\author{
Manuela Jörg-Ciopor, $M D^{b}$ \\ Mehdi Namdar, $\mathrm{MD}^{\mathrm{b}}$ \\ Jurai Turina, $M D^{\mathrm{a}}$ \\ Rolf Jenni, MD, MSEE ${ }^{a}$ \\ Jürg Schwitter, $M D^{a}$ \\ Marko Turina, $\mathrm{MD}^{\mathrm{c}}$ \\ Otto M. Hess, MD \\ Philipp A. Kaufmann, $M D^{b}$
}

From the Departments of Cardiology, ${ }^{\mathrm{a}} \mathrm{Nu}-$
clear Cardiology, ${ }^{\mathrm{b}}$ and Cardiothoracic Sur-
gery, ${ }^{\mathrm{c}}$ University Hospital, Zürich, Switzer-
land, and the Department of Cardiology,
Swiss Heart Center, Berne, Switzerland.

Received for publication April 21, 2003; revisions received July 12, 2003; accepted for publication Nov 4, 2003.

P.A.K. was funded by a grant from the Swiss National Science Foundation (SNFProfessorship). The study was supported by a grant from the Stanley Thomas Johnson Foundation, Berne, Switzerland.

Address for reprints: Philipp Kaufmann, MD, Head, Nuclear Cardiology, Cardiovascular Center, University Hospital C NUK 32, Rämistr. 100, CH-8091 Zürich, Switzerland (E-mail: pak@usz.ch).

J Thorac Cardiovasc Surg 2004;128:163-9 $0022-5223 / \$ 30.00$

Copyright (9) 2003 by The American Association for Thoracic Surgery

doi:10.1016/j.jtcvs.2003.11.003
Objective: Chest pain is a common finding in patients with hypertrophic cardiomyopathy and can be observed in $40 \%$ to $50 \%$ of all patients. However, the pathogenesis of these ischemia-like symptoms is still unclear.

Methods: Twenty-two patients with hypertrophic cardiomyopathy and 15 controls underwent positron emission tomography for evaluation of regional myocardial perfusion and coronary flow reserve (hyperemic/baseline myocardial blood flow). Myocardial perfusion $\left(\mathrm{mL} / \mathrm{min} / \mathrm{g}\right.$ ) was measured using $\left[{ }^{13} \mathrm{~N}\right] \mathrm{ammonia}$ at rest and during hyperemia with dipyridamole $(0.56 \mathrm{mg} / \mathrm{kg}$ intravenously). Regional coronary flow reserve was assessed in 3 planes (apical, midventricular, basal) in 4 regions (septal, anterior, lateral, inferior). Patients were divided into 2 groups: group 1 consisted of 11 patients treated with surgical myectomy (age $56 \pm 10$ years) and group 2 consisted of 11 patients treated medically (age $53 \pm 13$ years).

Results: Mean global coronary flow reserve was $3.87 \pm 0.92$ in controls but $2.31 \pm$ 0.40 in operated $(P<.001$ vs controls $)$ and $1.76 \pm 0.58$ in medically treated patients $(P<.001$ vs controls, $P<.05$ vs operated). Similarly, septal coronary flow reserve was $4.19 \pm 1.22$ in controls but significantly reduced in operated patients $(2.26 \pm$ $0.48, P<.001$ vs controls $)$ and in medically treated patients $(1.76 \pm 0.58 ; P<.001$ vs controls). However, septal flow reserve was significantly higher in operated patients than in patients with medically treated hypertrophic cardiomyopathy $(+37 \%, P<.05)$, mainly due to a reduced resting myocardial perfusion.

Conclusions: Global and regional myocardial perfusion is reduced in patients with hypertrophic cardiomyopathy. However, myectomy may have a beneficial effect on septal perfusion and flow reserve. Thus, ischemia seems to play an important role in the symptomatology and pathophysiology of hypertrophic cardiomyopathy.

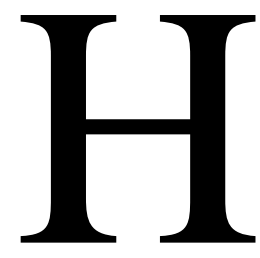

ypertrophic cardiomyopathy (HCM) is a progressive disease with significant morbidity and mortality. Sudden unexpected death can be the first clinical manifestation of HCM and is the most devastating feature in the natural history of the disease. Occurrence of sudden cardiac death has been reported to be about $2 \%$ to $3 \%$ per year. ${ }^{1}$ Approximately $60 \%$ to $70 \%$ of all patients with this disease die suddenly. Hemodynamic and electrophysiological studies in patients with HCM 
have demonstrated several potential mechanisms for cardiac arrest or sudden death, including atrial arrhythmias associated with hypotension, bradyarrhythmias, and ventricular tachyarrhythmias, all of which can be exacerbated in the presence of left ventricular outflow tract obstruction or myocardial ischemia. ${ }^{2}$ Chest pain and signs of ischemia have been found to occur frequently. ${ }^{3}$ In HCM, similarly to severe secondary left ventricular hypertrophy, the metabolic demands of the increased left ventricular muscle mass cannot be met by a parallel increase in coronary luminal area. ${ }^{4}$ As a consequence of left ventricular hypertrophy, large epicardial coronary arteries are dilated, which leads to a reduced coronary vasodilator capacity ${ }^{5}$ and impaired flow reserve, resulting in an underperfusion during high demand conditions. The pathophysiology of myocardial perfusion in the HCM muscle area may be crucial for sudden cardiac death. Camici and coworkers ${ }^{6}$ reported an impaired coronary vasodilator reserve in both hypertrophied and nonhypertrophied regions of the left ventricle in HCM using positron emission tomography (PET), suggesting that ischemia may result from abnormalities of the coronary microcirculation. This is supported by postmortem ${ }^{2}$ and ex vivo ${ }^{7}$ analyses of HCM hearts where an abnormal thickening of the arteriolar wall and a decreased capillary density were found with progressive left ventricular hypertrophy.

Surgical management of HCM was first introduced by Cleland, ${ }^{8}$ who performed myotomy/myectomy of the hypertrophied septum using a transventricular approach. This technique was later adapted by others, and transaortic myectomy has become the treatment of choice for severely symptomatic patients with large outflow tract pressure gradients, ${ }^{9}$ which is a strong, independent predictor of progression to severe symptoms of heart failure and of death. ${ }^{10}$ Septal myectomy has been associated with an improvement in symptoms and an increase in exercise capacity, but whether it prevents septal ischemia by changing the perfusion pattern, and thus prolongs life, remains unclear.

The aim of the present study was to evaluate the influence of surgical myectomy on regional and global perfusion and to compare it to medically treated patients with HCM.

\section{Methods}

The study protocol was approved by the local ethics committee. The investigation conforms with the principle outlines in the Declaration of Helsinki. Each volunteer signed the informed consent form after the investigative nature of the study and its risks and merits had been carefully explained.

\section{Study Population}

A total of 22 patients with HCM were studied: 11 had undergone surgical myectomy (HCM op) $13 \pm 5$ years ago and 11 were medically treated (HCM med). Mean age was $56 \pm 10$ and $54 \pm$ 13 years for operated patients and medically treated patients, respectively $(P=\mathrm{NS})$. All medication was withdrawn 48 hours before the study. Six patients operated for HCM were treated with the calcium channel blocker verapamil and 3 with beta-blockers, whereas 3 of the medically treated patients were on each of these treatment options. In the medically treated group angina pectoris was present in 4 , dyspnea in 5, and syncope in 3 patients. Dyspnea was reported in 5 operated patients during the postoperative follow-up. Prior to myectomy, however, all patients were symptomatic with either dyspnea (7 patients) or angina ( 7 patients) or syncope ( 8 patients) or a combination of these. The policy for conservative (medical) or surgical treatment remained unchanged at our hospital over the years of the study and was as follows. (1) Patients with a significant pressure gradient $(>25$ but $<50 \mathrm{~mm}$ $\mathrm{Hg}$ ) or typical symptoms that responded well to medical therapy were followed on medical treatment. (2) Patients were treated surgically if they had a resting pressure gradient of more than 50 $\mathrm{mm} \mathrm{Hg}$ or a pressure gradient after postextrasystolic potentiation of more than $100 \mathrm{~mm} \mathrm{Hg}$ or when clinical symptoms were present that did not respond or insufficiently responded to medical therapy. The same operator performed surgical myectomy in all patients by the transaortic/transventricular approach throughout the years. None of the patients was treated by transcatheter alcohol ablation.

Fifteen volunteers without cardiovascular disease served as controls (mean age of $34 \pm 14$ years; $P<.01$ vs HCM). None of the controls had a history of cardiovascular disease or risk factors. Entrance criteria included normal heart rate, blood pressure, normal resting electrocardiogram (ECG), and low clinical probability for coronary artery disease. ${ }^{11}$

The study was performed after overnight fasting. All subjects were carefully instructed to refrain from caffeine intake within 24 hours before the study.

\section{Study Protocol}

All volunteers were injected with 700 to $900 \mathrm{MBq}\left[{ }^{13} \mathrm{~N}\right] \mathrm{ammonia}$ into a peripheral vein by bolus technique while acquisition of the serial transaxial tomographic images of the heart was started. The 20 -minutes acquisition scan was followed by a 20 -minute transmission scan for photon attenuation correction using external ${ }^{68} \mathrm{Ge}$ sources. This was followed by an intravenous infusion of dipyridamole $(140 \mu \mathrm{g} / \mathrm{kg} / \mathrm{min})$ over 4 minutes and a second bolus of 700 $\mathrm{MBq}\left[{ }^{13} \mathrm{~N}\right]$ ammonia, which was injected 8 minutes after starting of the dipyridamole infusion.

\section{PET Scanning}

All images were acquired on a General Electric positron emission tomograph, which records 35 image planes simultaneously. The axial field of view is $14.5 \mathrm{~cm}$. A 30-minute blank scan was recorded as part of the daily routine procedures. Correct positioning of the volunteer's heart within the axial field of view of the tomograph was ascertained on a 4-minute rectilinear transmission scan. Starting with the intravenous administration of $\left[{ }^{13} \mathrm{~N}\right]$ ammonia, 12 frames of 10 seconds each, 4 of 30 seconds, 1 of 60 seconds, and 2 of 300 seconds were recorded.

\section{Data Analysis}

The transaxially acquired images were reoriented to obtain shortaxis images of the heart. A basal, a midventricular, and an apical slice were then chosen for further analysis. In each slice a region 
of interest (ROI) was placed within the septal, anterior, lateral, and inferior segments.

\section{Estimates of Myocardial Blood Flow}

A spherical ROI was placed into the blood pool of the left ventricle. Myocardial and blood pool time-activity curves were generated from the dynamic frames and corrected for radioisotope decay. Myocardial blood flow (MBF) was estimated by model fitting of the blood pool and myocardial time-activity curves using a 3-compartment model. ${ }^{12}$

The corrections for partial volume and spillover (both accounting for the resolution distortion) have been performed using the method described and validated by Hutchins and coworkers. ${ }^{13}$ Briefly, the ROI is chosen to contain only myocardial tissue and blood and, thus, the relation between the measured PET counts in a region $\left(\mathrm{C}_{\mathrm{PET}}\right)$ and the true counts in myocardium $\left(\mathrm{C}_{\mathrm{m}}\right)$ and arterial blood $\left(\mathrm{C}_{\mathrm{a}}\right)$ is modeled as follows: $\mathrm{C}_{\mathrm{PET}}(t)=\mathrm{F}_{\mathrm{a}} \mathrm{C}_{\mathrm{a}}(t)$ $+\left(1-\mathrm{F}_{\mathrm{a}}\right) \mathrm{C}_{\mathrm{m}}(t) . \mathrm{F}_{\mathrm{a}}$ is the fractional contribution of the blood pool to measured PET counts in a region and is dependent on the placement of the region, the resolution of the camera, and movement of the myocardium. Because the contribution of myocardium to total regional counts decreases with increasing blood pool fraction, $\mathrm{cm}$ is multiplied with $\left(1-\mathrm{F}_{\mathrm{a}}\right) . \mathrm{F}_{\mathrm{a}}$ is estimated together with the other kinetic tissue parameters using least-squares fitting.

Coronary flow reserve (CFR) was calculated as the ratio of hyperemic to resting MBF for global and regional MBF values. To account for the variability of coronary driving pressure, coronary resistance $(\mathrm{mm} \mathrm{Hg} / \mathrm{mL} / \mathrm{min} / \mathrm{g}$ ) was also calculated as the ratio of mean arterial pressure to MBF as previously reported. ${ }^{14}$

\section{Statistical Analysis}

Statistical comparison of hemodynamic data, MBF, and CFR were carried out by a 1-way analysis of variance for repeated measurements. When the analysis was significant, the Scheffé procedure was applied. Data are reported as mean values \pm standard deviation (SD) if not otherwise stated.

\section{Results}

All procedures were well tolerated apart from the common side effects caused by dipyridamole. None of the subjects experienced any ECG changes during the procedure.

\section{Echocardiographic Data}

In the operated patients preoperative gradients were $63 \pm$ $15 \mathrm{~mm} \mathrm{Hg}$. The postoperative data (Table 1) show that in operated patients compared with medically treated patients there was a tendency to smaller interventricular septal wall thickness and lower fractional shortening and pressure gradient, which fell short of statistical significance. Left ventricular end-diastolic chamber diameter did not differ between the 2 groups (Table 1). Six of the medically treated patients had no outflow tract obstruction and 5 had a gradient of $26 \pm 17 \mathrm{~mm} \mathrm{Hg}(63 \pm 16 \mathrm{~mm} \mathrm{Hg}$ during Valsalva maneuver).
TABLE 1. Echocardiographic data

\begin{tabular}{|c|c|c|c|}
\hline & HCM op & HCM med & $P$ \\
\hline IVS (mm) & $19 \pm 8$ & $24 \pm 5$ & NS \\
\hline PW (mm) & $13 \pm 3$ & $12 \pm 3$ & NS \\
\hline LVEDD (mm) & $47 \pm 4$ & $45 \pm 5$ & NS \\
\hline FS $(\%)$ & $37 \pm 8$ & $45 \pm 9$ & NS \\
\hline SAM (yes/no) & $3 / 8$ & $4 / 7$ & NS \\
\hline$\Delta \mathrm{P}(\mathrm{mm} \mathrm{Hg})$ & $8 \pm 16$ & $20 \pm 32$ & NS \\
\hline $\mathrm{HR}$ & $66 \pm 9$ & $74 \pm 10$ & NS \\
\hline SBP & $120 \pm 15$ & $120 \pm 8$ & NS \\
\hline DBP & $70 \pm 10$ & $74 \pm 10$ & NS \\
\hline RPP & $7982 \pm 1456$ & $8175 \pm 1731$ & NS \\
\hline
\end{tabular}

IVS, Interventricular septum; $P W$, posterior wall; $L V E D D$, left ventricular end-diastolic diameter; $F S$, fractional shortening; $S A M$, systolic anterior motion of the anterior mitral leaflet; $\Delta P$, pressure gradient; $H R$, heart rate; $S B P$, systolic blood pressure; $D B P$, diastolic blood pressure; $R P P$, rate pressure product; $N S$, not significant.

\section{Hemodynamics}

Heart rate, systolic and diastolic pressure, as well as rate pressure product (RPP) were comparable in the 3 groups. Under dipyridamole infusion RPP increased significantly after dipyridamole in controls $(11520 \pm 2124$ vs $7424 \pm$ $815, P<.01)$, in patients who had undergone surgical myectomy $(9840 \pm 2450$ vs $7720 \pm 850, P<.01)$ and in medically treated patients $(10671 \pm 1483$ vs $8083 \pm 1678$, $P<.01)$. There was no significant difference between RPP of the 3 groups after dipyridamole.

\section{MBF and CFR}

Global MBF at baseline was similar in controls $(0.72 \pm$ $0.20 \mathrm{~mL} / \mathrm{g} / \mathrm{min})$ and operated patients $(0.67 \pm 0.15 \mathrm{~mL} / \mathrm{g} /$ $\mathrm{min})$ but higher in medically treated patients $(0.89 \pm 0.21$ $\mathrm{mL} / \mathrm{g} / \mathrm{min}, P<.01$ vs both). Dipyridamole induced a significant increase in MBF in controls $(3.04 \pm 1.00 \mathrm{~mL} / \mathrm{g} /$ min, $P<.0001$ vs baseline) and in patients with hypertrophic cardiomyopathy $(P<.005)$. However, the response was significantly reduced in operated patients $(1.55 \pm 0.39$ $\mathrm{mL} / \mathrm{g} / \mathrm{min})$ and medically treated patients $(1.49 \pm 0.47$ $\mathrm{mL} / \mathrm{g} / \mathrm{min}$, both $P<.001$ vs controls; Figure 1). This resulted in a global CFR of $3.87 \pm 0.92$ for controls, $2.31 \pm$ 0.40 for operated patients $(P<.001$ vs controls), and 1.76 \pm 0.58 for medically treated patients $(P<.001 \mathrm{vs}$ controls, $P<.05$ vs operated patients), respectively (Table 2 ).

Septal MBF was $0.90 \pm 0.27 \mathrm{~mL} / \mathrm{g} / \mathrm{min}$ in controls, 0.68 $\pm 0.14 \mathrm{~mL} / \mathrm{g} / \mathrm{min}$ in operated patients $(P<.05$ vs controls $)$, and $0.87 \pm 0.18 \mathrm{~mL} / \mathrm{g} / \mathrm{min}$ in medically treated patients $(P$ $<.05$ vs operated patients). Hyperemic MBF was significantly larger in controls $(3.78 \pm 1.67)$ than operated patients $(1.54 \pm 0.33, P<.001$ vs controls $)$ or medically treated patients $(1.40 \pm 0.45, P<.001$ vs controls $)$, respectively (Figure 1). Septal CFR was $4.19 \pm 1.22$ in controls, but significantly reduced in operated patients $(2.26 \pm 0.48$, 

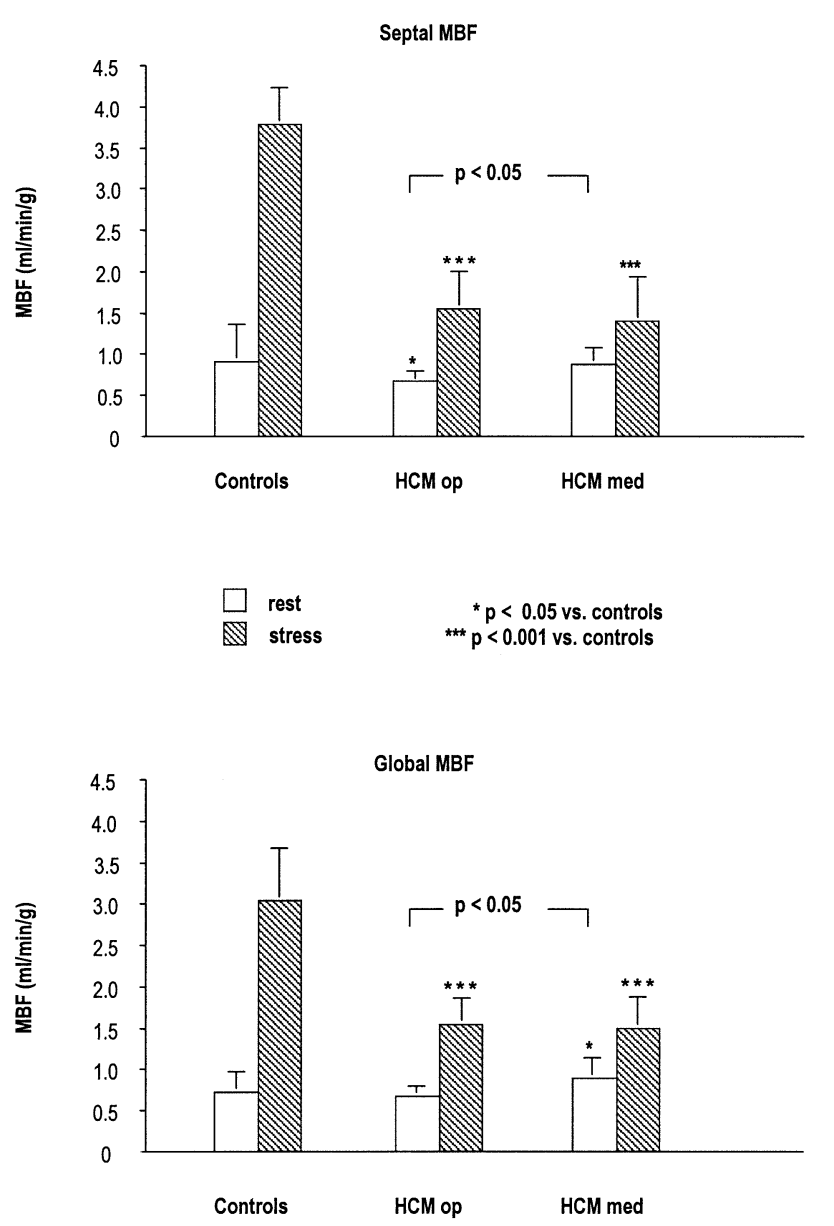

Figure 1. Septal and global MBF. Septal and global myocardial blood flow (MBF) are given at rest and during dipyridamoleinduced hyperemia (stress) for controls, operated patients (HCM op), as well as medically treated patients with hypertrophic cardiomyopathy (HCM med). Global as well as septal hyperemic response are largely blunted in HCM.

$P<.001$ vs controls) and medically treated patients $(1.65 \pm$ $0.53 ; P<.001$ vs controls). CFR was significantly higher in operated than medically treated patients $(+37 \%, P<.05)$. Furthermore, the difference in CFR between the lateral free wall and the septum was larger in medically treated patients, namely $16 \%(P<.05$ vs controls $)$ compared with $7 \%$ in operated patients and $-5 \%$ in controls (Figure 2).

\section{Influence of Outflow Tract Gradient on Maximal}

\section{MBF, CFR, and Coronary Resistance}

In the medically treated group patients with outflow tract obstruction, maximal hyperemic MBF was significantly lower in septal $(1.1 \pm 0.3 \mathrm{~mL} / \mathrm{min} / \mathrm{g}$ vs $1.7 \pm 0.4 \mathrm{~mL} / \mathrm{min} / \mathrm{g}$; $P<.05)$ and lateral segments $(1.3 \pm 0.3 \mathrm{~mL} / \mathrm{min} / \mathrm{g}$ vs 2.0 $\pm 0.6 \mathrm{~mL} / \mathrm{min} / \mathrm{g} ; P<.05)$ compared with patients without

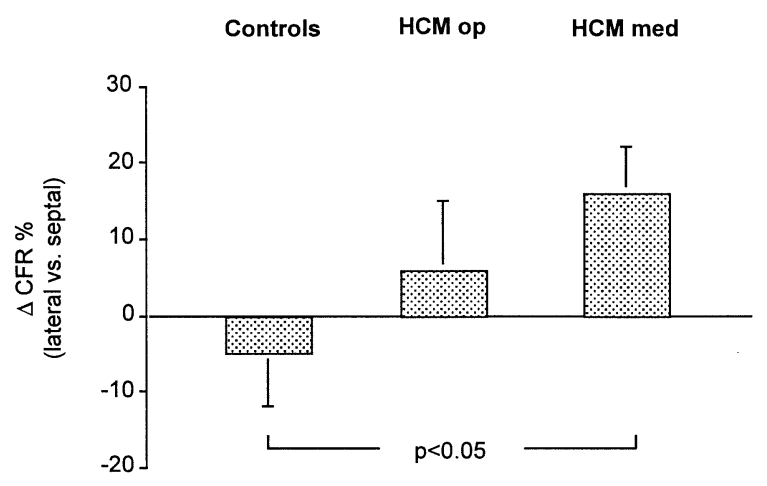

Figure 2. Difference between lateral and septal CFR. Controls and operated patients with hypertrophic cardiomyopathy (HCM op) have only modest regional difference between septal and lateral coronary flow reserve (CFR). By contrast, in medically treated patients with hypertrophic cardiomyopathy (HCM med) this difference is significantly larger.

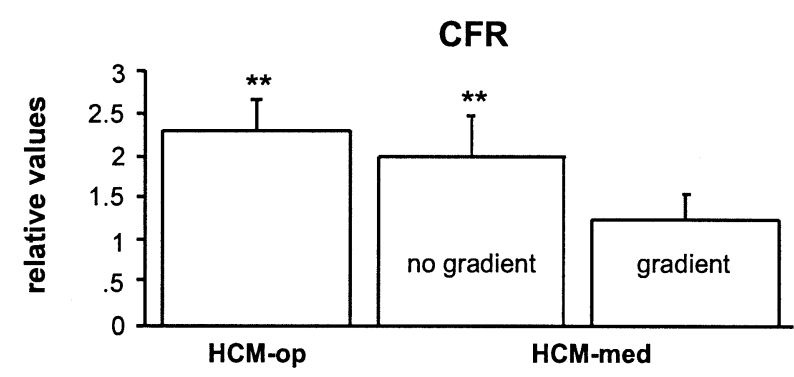

Figure 3. Influence of outflow tract gradient on vasodilatory response. Hyperemic MBF and CFR were significantly lower and minimal resistance significantly higher in medically treated patients with hypertrophic cardiomyopathy (HCM med) with gradient compared with HCM med without gradient as well as compared with operated patients with hypertrophic cardiomyopathy (HCM op). ${ }^{* *} P<.01$ vs HCM med with gradient.

outflow tract obstruction. Accordingly, in comparison with nonoperated patients gradient maximal hyperemic blood flow was significantly improved after myectomy in septal $(1.6 \pm 0.3 \mathrm{~mL} / \mathrm{min} / \mathrm{g}$ vs $1.2 \pm 0.3 \mathrm{~mL} / \mathrm{min} / \mathrm{g}, P<.05)$ and lateral $(1.8 \pm 0.4 \mathrm{~mL} / \mathrm{min} / \mathrm{g}$ vs $1.4 \pm .3 \mathrm{~mL} / \mathrm{min} / \mathrm{g}, P<.05)$ segments as was global CFR (Figure 3).

After myectomy minimal septal coronary resistance was significantly lower compared with nonoperated patients with outflow tract obstruction $(57 \pm 10 \mathrm{~mm} \mathrm{Hg} / \mathrm{mL} / \mathrm{min} / \mathrm{g}$ vs $79 \pm 21 \mathrm{~mm} \mathrm{Hg} / \mathrm{mL} / \mathrm{min} / \mathrm{g}, P<.05$ ), reaching values comparable to those found in patients without gradient (52 $\pm 5 \mathrm{~mm} \mathrm{Hg} / \mathrm{mL} / \mathrm{min} / \mathrm{g}$ ). In controls minimal coronary resistance was significantly lower compared with either group of patients with $\mathrm{HCM}(34 \pm 14 \mathrm{~mm} \mathrm{Hg} / \mathrm{mL} / \mathrm{min} / \mathrm{g} ; P<$ $.01)$. 
TABLE 2. MBF and CFR measurements

\begin{tabular}{|c|c|c|c|c|c|c|c|c|c|}
\hline & \multicolumn{3}{|c|}{ Controls } & \multicolumn{3}{|c|}{ HCM-ор } & \multicolumn{3}{|c|}{ HCM-med } \\
\hline & sep & lat & glob & sep & lat & glob & sep & lat & glob \\
\hline MBF-re & $0.90 \pm 0.27$ & $0.75 \pm 0.28$ & $0.72 \pm 0.20$ & $0.68 \pm 0.14 \dagger$ & $0.70 \pm 0.16$ & $0.67 \pm 0.15$ & $0.87 \pm 0.18^{*}$ & $0.89 \pm 0.20^{*}$ & $0.89 \pm 0.21 \dagger^{*}$ \\
\hline MBF_-stress & $3.78 \pm 1.67$ & $2.70 \pm 0.82$ & $3.04 \pm 1.00$ & $1.54 \pm 0.33 \S$ & $1.70 \pm 0.42 \ddagger$ & $1.55 \pm 0.39 \S$ & $1.40 \pm 0.45 \S$ & $1.63 \pm 0.60 \ddagger$ & $1.49 \pm 0.47 \S$ \\
\hline CFR & $4.19 \pm 1.22$ & $3.81 \pm 1.06$ & $3.87 \pm 0.92$ & $2.26 \pm 0.48 \S$ & $2.42 \pm 0.49 \ddagger$ & $2.31 \pm 0.40 \S$ & $1.65 \pm 0.53 \S^{*}$ & $1.89 \pm 0.70 \S$ & $1.76 \pm 0.58 \S$ \\
\hline
\end{tabular}

Stress, Pharmacologic stress with intravenous dipyridamole $(0.56 \mathrm{mg} / \mathrm{kg})$; sep, septal; lat, lateral; glob, global.

Values of $\mathrm{MBF}$ are given as $\mathrm{mL} / \mathrm{min} / \mathrm{g}$; values of CFR are relative values.

${ }^{*} P<.05$ vs controls.

† $P<.01$ vs controls.

$\ddagger P<.001$ vs controls.

$\S P<.05$ vs patients surgically treated for hypertrophic cardiomyopathy.

\section{Discussion}

The results of the present study confirm and extend previous observations of reduced CFR in HCM. In moderately symptomatic patients with HCM but without evidence for coronary artery disease we found a decreased CFR in agreement with earlier reports. ${ }^{3,6,7}$ Similarly to Camici and coworkers, ${ }^{6}$ CFR after dipyridamole stress was impaired in both hypertrophic and nonhypertrophic regions (ie, lateral free wall). This suggests a primary abnormality of the coronary bed as a cause for the blunted coronary flow response. Additionally, we found a relative reduction of septal CFR compared with the lateral wall in medically treated patients with HCM, supporting results from Grover-McKay and colleagues, ${ }^{15}$ who found significantly reduced $\left[{ }^{13} \mathrm{~N}\right]$-ammonia concentrations in the septum compared with the lateral wall of the left ventricle in HCM, while the opposite pattern is commonly found in normal volunteers. ${ }^{16}$ Our study is the first to investigate the impact of myectomy on regional myocardial perfusion. After surgical myectomy the observed difference between septal and lateral CFR was abolished despite the globally higher CFR in operated patients with HCM (Figure 2). Septal CFR was significantly higher in operated patients than in medically treated patients, although CFR in both groups remained significantly reduced compared with controls.

\section{Determinants of CFR}

CFR, defined as the ratio of near maximal to basal MBF, has been proposed as an indirect parameter to evaluate the function of the coronary circulation. It is an integrated measure of coronary flow through both the large epicardial coronary arteries and the microcirculation. A decrease in CFR can be due to the narrowing of epicardial coronary arteries - which was excluded in the present study, however-or to microvascular dysfunction. ${ }^{17}$ The latter can theoretically be caused by several mechanisms: (1) structural changes (ie, vascular remodeling with reduced lumen to wall ratio) or functional alterations involving neurohumoral factors; (2) small coronary arterioles may change their diameter as a result of autonomic innervation ${ }^{18}$; (3) several extravascular mechanisms such as impaired diastolic relaxation, compression of the coronary arteries by high left ventricular filling pressures, and increased force of contraction ("milking").

\section{Mechanisms of Impaired CFR in HCM: Role of Myectomy}

Although the precise mechanism of myocardial ischemia in individual patients with HCM is not clear, a number of pathophysiologic features have been found to cause a mismatch between oxygen supply and demand, including increased myocardial muscle mass, reduced capillary density, ${ }^{7}$ and "small vessel disease." ${ }^{, 715}$ Recently, Schafers and coworkers ${ }^{19}$ documented presynaptic and postsynaptic autonomic dysfunction in HCM, with increased local catecholamine levels and down-regulation of myocardial betaadrenergic receptors, which could contribute to microcirculatory dysregulation. Left ventricular diastolic dysfunction in HCM has the potential to cause myocardial ischemia probably by causing a maldistribution of transmyocardial blood flow, with a reduced subendocardial/ subepicardial flow ratio after dipyridamole infusion. ${ }^{20} \mathrm{An}$ outflow tract obstruction is associated with reduced maximal hyperemic flow. Myectomy may exert its beneficial effect on CFR by reducing extravascular compressive forces as a result of improved diastolic relaxation, reduced force of contraction, and, thus, reduced compression of the coronary arteries. These mechanisms may not be entirely limited to the septum and therefore may have some influence on global CFR, as evidenced by the higher global CFR in operated patients compared with medically treated patients without outflow tract obstruction.

CFR is defined as ratio of hyperemic to resting MBF and therefore may be susceptible to changes in the denominator (ie, the resting flow). Resting MBF was significantly lower in operated patients than medically treated HCM patients. However, the absolute hyperemic flow data (Table 2) further substantiate the CFR data, as operated patients had significantly higher hyperemic MBF compared with medically treated patients with obstruction. 
Accordingly, septal coronary resistance, which was calculated to account for the driving pressure, was significantly higher in medically treated patients with outflow tract obstruction compared with those without obstruction and was significantly reduced after myectomy. This is illustrated best in Figure 2, showing that the difference in CFR between the lateral free wall and septum is maximal in subjects with gradient. Thus, our data confirm that myectomy improved vasodilator response in HCM, most probably due to the removal of the obstruction, although it cannot be ruled out that the 2 groups of patients with HCM did not start off at the same point in the disease process. It is, however, unlikely that the differences in MBF and CFR between operated patients and medically treated patients were already present before myectomy as the gradient seems to play the major role. Only measurements before and after myectomy in the same patients would provide definitive answers.

The beneficial effect of myectomy on CFR adds evidence that ischemia may indeed play an important role in the symptomatology and pathophysiology of HCM. The significantly reduced maximal MBF and CFR in patients with HCM suggests that ischemia may occur during high coronary flow and oxygen demand situations such as mental stress or physical activity. This is supported by the clinical finding that chest pain was less common in operated patients with HCM (none of the patients) than in medically treated patients with $\mathrm{HCM}$ (4 patients; chi-square test: $P<.05$ ) and is in line with results of Cannon and coworkers, ${ }^{21}$ who reported a net lactate release in the coronary sinus during atrial pacing as a biochemical substrate for the simultaneously documented reversible defects in thallium-201 scanning.

\section{Study Limitations}

The large differences in wall thickness between patients with HCM and controls may affect the correct interpretation of the flow data due to differences in partial volume effects. To minimize these effects, we have corrected for partial volume effects by applying the method proposed by Hutchins and coworkers. ${ }^{13}$ The partial volume effect is extremely important in thin walls of less than $5 \mathrm{~mm}$ but less problematic in hypertrophic hearts with thick walls. ${ }^{13}$

Patients with HCM were significantly older than the controls. This may have affected our results. In fact, Czernin et $\mathrm{al}^{22}$ found a gradual decline in CFR with aging. This was, however, primarily due to increased cardiac work and blood flow at rest rather than to an abnormal vasodilator capacity (since dipyridamole-induced hyperemic flow was not affected by aging). This does clearly not apply to our study, where baseline MBF was lower in patients with HCM despite their higher age. In addition, Uren and coworkers ${ }^{23}$ reported that $\mathrm{MBF}$ at rest and during hyperemia (and thus
CFR) are roughly comparable up to 60 years of age. In the age group of 50 to 59 years, CFR tended to be maximal and even slightly higher than in the age group of 30 to 39 years (ie, our control group's age). Thus, CFR would be expected to be higher in both HCM groups, rather than lower, compared with the younger controls, a fact that strengthens even further our results.

Differences in medical treatment between operated and medically treated HCM may represent a confounding factor for direct comparison of these groups. Indeed, 6 patients operated for HCM were treated with the calcium channel blocker verapamil, whereas only 3 of the medically treated patients were on this treatment. However, although verapamil has beneficial effects on the left ventricular relaxation $^{24}$ and on transmural MBF distribution in $\mathrm{HCM},{ }^{25}$ it has no effect on total MBF as assessed with PET. ${ }^{26}$

\section{Conclusions}

Global as well as septal CFR is reduced in patients with HCM. However, myectomy seems to have a beneficial effect on septal perfusion and CFR. Thus, ischemia may play an important role in the symptomatology and pathophysiology in HCM.

\section{References}

1. Maron BJ, Fananzapir L. Sudden cardiac death in hypertrophic cardiomyopathy. Circulation. 1992;85(Suppl):157-63.

2. Maron BJ, Epstein SE, Roberts WC. Hypertrophic cardiomyopathy and transmural myocardial infarction without significant atherosclerosis of the extramural coronary arteries. Am J Cardiol. 1979;43:1086102.

3. Pasternac A, Noble J, Streulens Y, Elie R, Henschke C, Bourassa MG. Pathophysiology of chest pain in patients with cardiomyopathies and normal coronary arteries. Circulation. 1982;65:778-89.

4. Kaufmann P, Vassalli G, Lupi WS, Jenni R, Hess OM. Coronary artery dimensions in primary and secondary left ventricular hypertrophy. J Am Coll Cardiol. 1996;28:745-50.

5. Vassalli G, Kaufmann P, Villari B, Jakob M, Boj H, Kiowski W, et al. Reduced epicardial coronary vasodilator capacity in patients with left ventricular hypertrophy. Circulation. 1995;91:2916-23.

6. Camici P, Chiriatti G, Lorenzoni R, Bellina RC, Gistri R, Italiani G, et al. Coronary vasodilation is impaired in both hypertrophied and nonhypertrophied myocardium of patients with hypertrophic cardiomyopathy: a study with nitrogen-13 ammonia and positron emission tomography. J Am Coll Cardiol. 1991;17:879-86.

7. Krams R, Kofflard MJM, Duncker DJ, Von Birgelen C, Carlier S, Kliffen M, et al. Decreased coronary flow reserve in hypertrophic cardiomyopathy is related to remodeling of the coronary microcirculation. Circulation. 1998;97:230-3.

8. Cleland WP. The surgical management of obstructive cardiomyopathy. J Cardiovasc Surg (Torino). 1963;4:4889-91.

9. Seiler C, Hess OM, Schoenbeck M, Turina J, Jenni R, Turina M, et al. Long-term follow-up of medical versus surgical therapy for hypertrophic cardiomyopathy: a retrospective study (see comments). J Am Coll Cardiol. 1991;17:634-42.

10. Maron MS, Olivotto I, Batocchi S, Casey SA, Lesser JR, Losi MA, et al. Effect of left ventricular outflow tract obstruction on clinical outcome in hypertrophic cardiomyopathy. N Engl J Med. 2003;348: 295-303.

11. Diamond G, Forrester J. Analysis of probability as an aid in the clinical diagnosis of coronary artery disease. N Engl J Med. 1979;300:1350-8.

12. Muzik O, Beanlands RS, Hutchins GD, Mangner TJ, Nguyen N, 
Schwaiger M. Validation of nitrogen-13-ammonia tracer kinetic model for quantification of myocardial blood flow using PET. J Nucl Med. 1993;34:83-91.

13. Hutchins GD, Caraher JM, Raylman RR. A region of interest strategy for minimizing resolution distortions in quantitative myocardial PET studies. J Nucl Med. 1992;33:1243-50.

14. Kaufmann PA, Gnecchi-Ruscone T, Schafers KP, Luscher TF, Camici PG. Low density lipoprotein cholesterol and coronary microvascular dysfunction in hypercholesterolemia. J Am Coll Cardiol. 2000;36: 103-9.

15. Grover-McKay M, Schwaiger M, Krivokapich J, Perloff JK, Phelps ME, Schelbert HR. Regional myocardial blood flow and metabolism at rest in mildly symptomatic patients with hypertrophic cardiomyopathy (see comments). J Am Coll Cardiol. 1989;13:317-24.

16. Hutchins GD, Schwaiger M. Quantitative evaluation of myocardial perfusion. In: Schwaiger M, editor. Cardiac emission tomography. Boston/Dordrecht/London: Kluwer Academic Publisher; 1996. p. 98118.

17. de Silva R, Camici PG. Role of positron emission tomography in the investigation of human coronary circulatory function. Cardiovasc Res. 1994;28:1595-612.

18. Zeiher AM, Drexler H, Wollschläger H, Saurbier B, Just H. Coronary vasomotion in response to sympathetic stimulation in humans: importance of the functional integrity of the endothelium. J Am Coll Cardiol. 1989;14:1181-90.

19. Schafers M, Dutka D, Rhodes CG, Lammertsma AA, Hermansen F, Schober O, et al. Myocardial presynaptic and postsynaptic autonomic dysfunction in hypertrophic cardiomyopathy. Circ Res. 1998;82:5762.

20. Camici PG, Cecchi RG, Montereggi A, Salvadori PA, Dolara A, L'Abbate A. Dipyridamole-induced subendocardial underperfusion in hypertrophic cardiomyopathy assessed by positron-emission tomography. Coron Artery Dis. 1991;2:837-41.

21. Cannon RO III, Dilsizian V, O'Gara PT, Udelson JE, Schenke WH, Quyyumi A, et al. Myocardial, metabolic, hemodynamic, and eletrocardiographic significance of reversible thallium-201 abnormalities in hypertrophic cardiomyopathy. Circulation. 1991;83:1660-7.

22. Czernin J, Muller P, Chan S, Brunken RC, Porenta G, Krivokapich J, et al. Influence of age and hemodynamics on myocardial blood flow and flow reserve. Circulation. 1993;88:62-9.

23. Uren NG, Camici PG, Melin JA, Bol A, de Bruyne B, Radvan J, et al. Effect of aging on myocardial perfusion reserve. J Nucl Med. 1995; 36:2032-6.

24. Hess OM, Murakami T, Krayenbuehl HP. Does verapamil improve left ventricular relaxation in patients with myocardial hypertrophy? Circulation. 1986;74:530-43.

25. Choudhury L, Elliott P, Rimoldi O, Ryan M, Lammertsma AA, Boyd $\mathrm{H}$, et al. Transmural myocardial blood flow distribution in hypertrophic cardiomyopathy and effect of treatment. Am J Cardiol. 1994;74: 363-8.

26. Gistri R, Cecchi F, Choudhury L, Montereggi A, Sorace O, Salvadori PA, et al. Effect of verapamil on absolute myocardial blood flow in hypertrophic cardiomyopathy. Am J Cardiol. 1994;74:363-8.

\section{The Journal of Thoracic and Cardiovascular Surgery Conflict of Interest Policy}

To assure fairness to authors submitting work for consideration in The Journal of Thoracic and Cardiovascular Surgery, a mechanism exists for managing conflicts of interest. The editor and each of the section editors complete a "Conflict of Interest" form that identifies any and all relationships with commercial and other academic entities. When the editor has a potential conflict because of a relationship with another entity or author, the editor appoints an alternate editor from among the section editors or editorial board members who assumes the entire responsibility for final decisions on the manuscript in question. The editor does not read the reviews that are submitted nor engage in discussing the manuscript prior to the final decision. When the conflict of interest involves a section editor, a "guest section editor" is appointed who fills the role normally played by the conflicted section editor. All members of the editorial board and reviewers are asked to indicate any conflict of interest when they agree to review a manuscript. 